\title{
Event-Sequences, Plots and Narration in Computer Games
}

\author{
by Fotis Jannidis
}

\begin{abstract}
Starting with the debate between ludologists and narratologists this essay tries to show that there is a narrative aspect in computer games which has nothing to do with background stories and cut scenes. A closer analysis of two sequences, taken from the MMORPG Everquest II and the adventure game Black Mirror, is the basis for a distinction between three aspects of this kind of narrative in computer games: the sequence of activities of the player, the sequence of events as it is determined by the mechanics of the game and this sequence of events understood as a plot, that is as a sequence of chronologically ordered and causally linked events. This kind of narrative is quite distant to the prototypical narrative which is the basis of most of the narratology. But actually all media, not only computer games, need their own narratology.
\end{abstract}

I.

Within the past eight years an intense discussion has been going on between two positions that usually are termed ludologist or narratologist, even though this discussion has not always been productive..$^{[1]}$ One point of departure was a paper by Gonzalo Frasca suggesting that outside of other viewpoints and especially beyond narratology computer games should also be seen as games. His goal was to complement existing viewpoints. However, an important part of the paper dealt with the question of the difference between game and narrative. Frasca introduced the term ludology "to refer to the yet non-existent 'discipline that studies game and play activities'. Just like narratology, ludology should also be independent from the medium that supports the activity. ("Ludology Meets Narratology" 2)."

However, it was the strategy of replacement implied in his argumentation that caught on rather than his suggestion to see ludology as an alternative to narratological perspectives. In his view computer games in principle are something else than narratives. If you want to analyze them you have to choose intellectual tools adapted to the special characteristics of games and these tools can only be provided by a type of scholarship that sees them first of all as games and that therefore resorts to game-theory for their analysis. $\frac{[2]}{T}$ To quote Eskelinen's unequivocal manner of speaking: "there is a crucial difference separating these practices from each other: in art we may have to configure in order to be able to interpret, whereas in games we have to interpret in order to be able to configure, and proceed from the beginning to the winning or some other situation" (197)

Especially on the part of the ludologists the debate was held with unusual stridency and polemics. Thus their representatives were accused to have mainly political reasons, i.e. trying to safeguard their exclusive claim for the newly created jobs analyzing computer games.

Narratologists have tried to describe computer games from the point of view of narrativity. One of their most astute representatives, Marie-Laure Ryan, has 
formulated the possibilities and limits of such an approach in the following way:

Are we then entitled to say that a computer game is, or can be a narrative? To parody former President Clinton, it all depends on what the meaning of "is" is. Those who deny narrativity to games on the ground that the point is to play, not to hear stories nor to produce a trace readable as narrative adhere to a narrow interpretation of the word "is," an interpretation that reduces the possible modes of participation of a text in a narrative representation to the traditional modes of literary narrativity. The inability of literary narratology to account for the experience of games does not mean that we should throw away the concept of narrative in ludology; it rather means that we need to expand the catalog of narrative modalities beyond the diegetic and the dramatic, by adding a phenomenological category tailor-made for games. ("Beyond Myth and Metaphor")

However, Ryan's position does not convince me for reasons that I will clarify immediately even though her suggestion regarding the challenge of narratology by computer games is decidedly worth some consideration.

One of the basic problems of her argument is not only the vagueness of some of the terminology used, as Frasca mentions quite correctly, but also the fact that the particular claims can hardly be negotiated rationally. Ludologists do not maintain that narratives do not play a role in computer games. They argue in particular, however, that the analysis of narratological aspects is not productive, since it is not really compatible with the dominant characteristics of computer games (cf. Eskelinen and Tronstad; Frasca, "Ludologists"). The comments of the ludologists regarding this general 'nature' of computer games are relatively imprecise; they are based on a wide-ranging phenomenology of computer games. Obviously in the ludologists' camp there is as much agreement about the fact what a computer game 'is', as there is agreement in the camp of narratologists what a narrative is.

To my mind, computer games have as much in common with conventional games as with narratives. In some aspects there are quite a lot of similarities, but in others they clearly diverge. Like games, computer games have rules and some of them also define the conditions of winning and loosing. On the other hand it is unusual for games that the worlds of the game are extensively formed or developed. The inventors of games are also in no way interesting for the players, since they only define the rules, whereas there are many computer games that to a large extent are attributed to a designer who can even have a cult status. The history of traditional games also cannot be used as a foundation for a film.

From these observations, however, we cannot necessarily deduct that computer games have to be attributed to the category of narration. As I will argue presently, quite a bit speaks against this conceptualization. I believe, however, that a perspective of computer games that sees them predominantly as games loses sight of some important aspects, as for example the mediality of computer games or their communicativity.

On the other hand the suggestions of the ludologists that narratives have a different function in games and that they are created differently than in traditional narrative media is decidedly worth some consideration. A problem in the discussions seems to be the double meaning of the term narration that is also mentioned by Ryan in her contribution. On the one hand narration signifies the medial representation of a self-contained storyline; on the other hand it means a sequence of chronologically ordered and causally linked events. This second meaning of narration in my opinion emerged in the process of a displacement; it therefore seems more plausible to use the term plot instead. For reasons that I have elaborated upon elsewhere I would conceptualize the term narration in its first meaning as prototypical ("Narratology and the 
Narrative"). This prototype roughly means that somebody narrates to others a concluded sequence of chronologically and causally connected events that have happened in the past. Related to this prototype of oral narration, literate narration is already a variant, connected to a change of medium. To my mind it is an advantage of this terminology that thereby the dependency on the medium remains obvious. Since the point of departure is a prototype in the case of film one does not have to ask any more who the 'narrator' is in the film, since it becomes clear how great the gap between this type of narration and the prototype already has become. $\underline{[4]}$

Let us come back to computer games. Their impressive diversity clearly has the effect that general statements valid for all computer games are quite abstract and do not open up a path for the analysis of individual works. Therefore in the following I would like to discuss the phenomena that interest me with the help of two examples representing two genres: Black Mirror (Adventure) and Everquest II (MMORPG). These games certainly contain plots, but unlike plots conforming to the prototype of narrative these game plots are not experienced as completed at the moment of playing the game.

The initial observation for the following ideas was an experience while playing ego-shooter Half-Life 2. In his fight against the invaders and while he is constantly running away from the security forces of the Quisling government the hero led by the player ends up in a labyrinth of courses of rivers and channels that he crosses with a speed boat. Times and again he is shot at from the air above or from the banks or has to dodge mines that just were planted. In this stressful situation we simply follow the course of the rivers and channels, always hoping that the next place might be a bit calmer than the one we have just left. At the same time it is obvious that one always knows where to go. The route through the system of channels is constructed in such a way that we can decide very quickly which is the correct way, since it is the continuing one that finally leads us to the next level. Where do we know this from?

Expressed differently and more generally: I am interested in a series of questions that are connected:

1. How does the player of a computer game know what to do next?

2. How are events in the game connected to an event-sequence that is relevant for the game?

3. How do these patterns and gameplay relate to each other? ${ }^{[5]}$

4. How are these event-sequences embedded in the game?

5. How do these event-sequences relate to 'narrativity'?

The different questions are connected to different perspectives of the game. In order to answer the first question the game has to be reconstructed from the perspective of the player at a certain point in the game. In order to answer the second question, we have to reconstruct the relevant mechanics of the game as a whole. The third question, the embedding of the event-sequences can be seen both in the context of other possible patterns of activity in the games and in the context of the story that is constituted by it and its relation to other stories connected to the game. All these questions initially have to be answered differently for each game, while the last question is aimed at a more general problem.

\section{II.}

Let us start with a simple example. In MMORPGs quests are tasks that the player receives from a quest giver and that are rewarded in the end. Games like Everquest II contain several thousands of quests. There are especially simple quests ("Go to place X and speak with NPC Y") and very complex series of quests. ${ }^{[6]}$ Quests are simple examples insofar as some of the above mentioned questions can be answered very quickly. Since in MMOPRGs several thousand PCs (player characters) and NPCs (non- player characters) can exist in the 
same virtual world it is by now an established convention to mark the quest givers graphically; accordingly the situation is unequivocal for the player before he even approaches a quest giver. Since quests in the games are tasks, which the player can take on if he is interested in the indicated reward, there is no uncertainty about the question when he receives the option to act. Our example, the quest "The Missing" ${ }^{\text {"7] }}$ is the first quest of a lengthy series at the end of which the player has activated a new 'race' and now on his own can create characters of this race. Within the world of the game these first three quests are aimed at the player's winning the trust of the quest giver.

The player gets the task of a quest giver in the context of a dialogue..$^{[8]}$

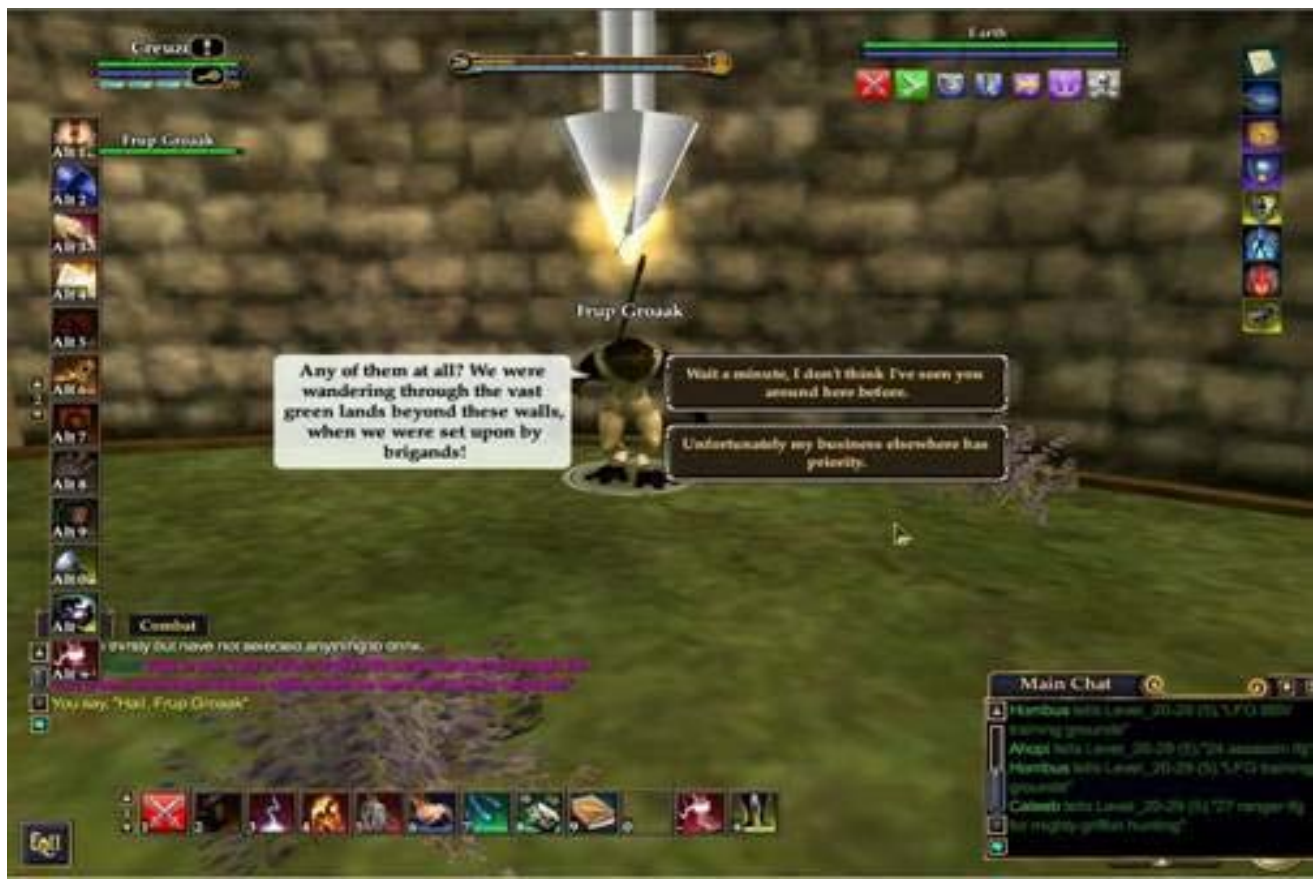

Fig. 1. Receiving a quest through a dialogue (in Everquest 2)

After he has accepted the quest it is entered into his quest-book that in a few sentences informs him about his task. If we compare the two sources of information in the present case we notice that in the quest-book only the name of the character to be found is given, but not a description of the place. The description of the place by the quest giver in the dialogue on the other hand dispenses with the usual names of the game, which are also visible on the map that each player has of many zones: "I apologize, I do not know the names of places here. T'was quite a ways south east of here, however. There was a great forest situated on the banks above." With some knowledge of the place the player then nevertheless is able to recognize the intended place; at least he will recognize roughly the direction in which he has to search. These instructions however are in no way clear enough for him to get all the information. On the contrary, in many cases quite a bit of knowledge about the game is necessary in order to interpret the clues correctly.

The respective events of the quests, often small tasks like "find the place $X$ " or "kill the monster $Y$ " are rather independent and the connections between the events are quite loose so that the player of a quest can interrupt his work on the quest at each point and can do something completely different. The player is informed about such a task in the quest through a clearly visible visual announcement, called a quest update in the jargon of games; subsequently quite often the description of the quest is changed in the diary. When the player is working on the quest "The Missing" after having received the command, he will search for the beach on which the missing Froglok was seen the last time. But at the beach he will not find the Froglok but tracks which he now has to follow. This pursuit in the game is staged in such a way that at the beginning he received a direction, i.e. "The Froglok tracks continue back to the East." This 
clue, however, is consciously vague and the player has to search in the indicated direction until he finds an object that he can click on. In this case it is relatively unproblematic, since the player has many levels more than the animals or the aggressive inhabitants of the area in which he has to search. In other quests it may be just this task to find ones way in a dangerous environment.

At the end of the search for tracks the player has finally found the missing Froglok and now has to lead him to the next watchtower. But this task cannot be completed successfully since his charge always dies shortly before reaching the watchtower. Only the changed entry in his quest-book tells him at this point what he now has to do: to return to the Quest Giver. Actually the player has successfully completed his quest despite his failure in the narrative and now has the possibility to start the subsequent quest.

How are the quests embedded in the game? Probably in this case we have to differentiate between two aspects. After the player has accepted the quest, he has two possibilities to act. He instantly can work on the quest or do something completely different. Even though quests are possible sequences of activity for a player they do not necessarily structure the game as a whole. In other words, quests may offer possibilities of meaning to the player, but he can and will at the same time accept many other possibilities. By himself or as a group he can collect experience points in order to reach the next level; he also can buy or sell things through the broker in order to make money or to improve his own equipment. He can also pursue a trade or he can harvest in order to sell his crop or use it in his trade. Quests, in other words, are relatively independent sequences of events and this means that it is not important for the game whether one follows a quest or not. In Everquest II there seems to be a tendency to abolish all quests relevant for the game. ${ }^{[9]}$ The only exceptions to this autonomy of quests are connecting quests that are only cleared and activated after the preceding quest has been completed. In this manner relatively long chains of quests can emerge.

Alongside this relatively tight embedding through a pattern of events that is made possible only by completing the quest there are still other forms. Everquest II, for example, knows an intricate faction system. Faction means the status of the player during a certain social unit of the game. If this status falls below a certain value the player is attacked by the members of this group. Quite often the result of quests is the fact that a player improves or worsens his status. Certain quests only are cleared or activated when the player has reached a very high status. In dialogues the player often gets clues that he has not yet acquired the 'trust' of the group to the extent to receive additional information.

Another form of embedding is achieved by the narrative elements. Everquest II is surrounded by and contains numerous lore and legends. Everquest II is the successor of the relatively successful game Everquest $I$. The setting is the same world as in Everquest $I$, but the time of action is 500 years later. Before the game was published on a website, a series of short prose texts were circulated that informed about the main events between Everquest $I$ and Everquest II. ${ }^{[10]}$ The events of this earlier frame narrative determine the game from several points of view, starting with the political factions and including the appearance of the world as well as the fact that a series of quests is even more or less closely related to events in this frame narrative.

The quest "The Missing" analyzed above refers to the narrative of the Frogloks. Only some years after Everquest I was on the market the Frogloks became a race that could be chosen by the players and they obtained their own city, Gukta. This was motivated by a frame story that narrated the eviction of the trolls who had been the original-of course 'evil'-inhabitants of the city. Between the two games a great battle of the evil forces took place that among others also conquered Gukta. But some Frogloks managed to flee, even though 
they lived in slavery for a long time and only lately a small community of free Frogloks was built. But the player does not receive this information at the beginning of this quest sequence but only after he has won the trust of the Quest Giver and when he has reached the secret subterranean city of the Frogloks. There he has to complete several additional quests in order to gain the trust of the Chief. One of these quests is finding the answers to a series of questions concerning a history lesson. ${ }^{[11]}$

The gameplay for the completion of quests mainly consists in moving the character through very dangerous environment, in finding objects and in killing monsters. The latter can often be very difficult since it necessitates a group (6 persons in all) or even a raid (totaling 24 persons).

How important then is the embedding of the sequence of events into a meaningful structure of the narrative? We can complete most of the quests without paying attention to this narrative and according to my observations this is the manner in which most players are playing. The reason probably is that the quests do not change the world of the game. The only change that can be achieved by the player is receiving his reward, $\frac{[12]}{}$ which is his main interest anyway. There are some signs that quests can change the world of the game for a certain time or even lastingly. Everquest I for example contains a zone in which a continuous war with battles between three parties is taking place and it is part of the assignments of the player to help one of the parties to a temporary victory. But it is clear that in this respect the design of the game conflicts with the story. From the point of view of design every player of a MMORPG is supposed to have the same possibilities, i.e. quests, as all the others. A story, however, put very simply, narrates - if it is worth telling at all-a fundamental alteration of the world.

III.

Black Mirror: The Dark Side of the Soul is a horror-adventure game that is not afraid of some strong splatter-effects. The player is leading the young nobleman Samuel Gordon who for the first time in many years returns to his ancestral castle. Samuel soon suspects that the alleged suicide of his grandfather was a murder. It seems to be somehow connected to a curse that William had investigated because it has haunted the family for many years: Every 200 years one of the family members goes insane. William had found out that this curse somehow is connected to five peculiar keys that are handed down in the family. The greatest part of the activities of the player consists in getting back these five keys, mostly from the graves of the respective family members. During Samuel's investigations a series of further murders occur which he is also trying to clear up. An added parallel plot concerns his uncle Robert who later is also murdered. He is the classical mad scientist who is using his position as the director of an insane asylum for lethal experiments on human beings. In the end Samuel finds out that he himself is the murderer. He succeeds in breaking the curse and commits suicide in order to atone for his sins. $\underline{[13]}$

The way in which this game is played as well as its technique makes it into a classical adventure game. The player receives a fixed 2D-view of each setting and can only change from one view to the next. The mouse helps to explore the image and changes its color for all active objects. The player can investigate all these objects and can take over some of them into his inventory or use them. Objects in the inventory often have to be combined with other objects. ${ }^{[14]}$

The section analyzed in the following is part of the narrative sequence in which Samuel receives the key from James, his unhappy uncle, whose mild insanity was reason enough for his brother Robert to put him into an insane asylum. As the player knows at this point in the game, James has hidden the key in the ancestral castle, in all probability in the intricate sewage system that could not be entered until now. 
The first image shows a turning wheel on a mechanism on its right hand side (fig. 2.). ${ }^{[15]}$ The mechanism cannot be operated and at this point the player would not even know why he should operate it. On the other hand, half-broken mechanisms that have to be repaired belong to the conventions of the genre. The player then can rightfully assume that this mechanism will significantly contribute in reaching his goal to collect all five keys.

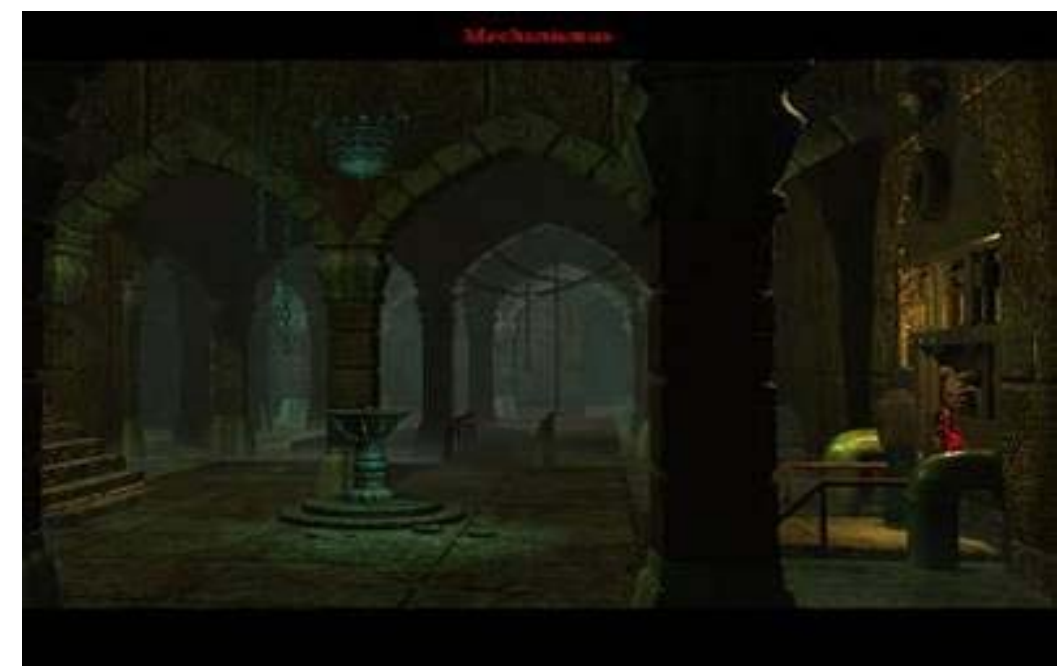

Fig. 2. Strange mechanism in Black Mirror as the next problem for the player.

One of the active objects in this image is the gear wheel on the floor. If you click on it, Samuel picks it up. The description of the gear wheel in the inventory: "Where could this fit?" indicates that the player has to fit it into something. The great similarity of the picked-up gear wheel with the one that is part of the mechanism provides a further clue to the player where he has to install it. After the installation, however, the mechanism still is not moveable. Another empty pin seems to imply that the player has to look for the third gear wheel in order to finally be able to get the mechanism going.

The player then finds what he is looking for on the second image of the sewage system, but he cannot reach it. This opens up another task that further delays the main task. In order to reach the gear wheel he first has to change the level of water; for this he needs a lever. And in order to be able to use the rod he found as a lever he first has to grind it down, etc.

One of the characteristics of Adventure Games is to give the player only vague hints what has to be done next. However, the goal of his activities is quite clear. ${ }^{[16]}$ It is only the way to the goal which is unclear. To find out which steps to take is one of the basic repertoires of the gameplay of Adventure Games. Part of these is the careful searching of the image for active objects and the combination of objects in the inventory with objects in the image as well as dialogues with characters and the solution of independent puzzles. In the search for solutions, however, several aspects support the player. It is especially his knowledge about the conventions of the genre and his knowledge of everyday life that limit the free permutation of all activity-options. The similarity of the gear wheels with the free pin for example works in this manner so that it does not make much sense to use the map or a coin on the gear wheel swimming in the water. This, however, is a scaleable dimension to which reviews of the game often refer with phrases like: "The riddles are logical." It is of prime importance for the player to know that there is a solution at all and that his hunt will be definitely successful at some point.

In many games not all objects are functional but exist only in order to enrich the world of the game; to a certain extent then they belong to the category that Roland Barthes has called reality effects enlarging the seeming options of activity for the player. The designers of Black Mirror therefore have chosen a middle way. Many of the non-functional objects cannot be activated any more after having been clicked on once or twice so that they are no longer 
activity-options.

The activities of the player create a sequence of events of which some are relevant for the game in order to allow for further steps. Therefore, as in the case of MMORPGs, we have to differentiate between the narrative sequence of the player and that on which the game is dependent with a minimal amount of steps for the solution. The one is accessible by means of narratives of players like: ". . . and then I searched for a long time until I found out that . . . ." The other by studying the code or the suggestions for solutions, the so-called walkthroughs.

The activities of the player and the events in the world of the game are more closely related than in a MMORPG. As I have already mentioned: Even though the gameplay mostly consists of the combination of objects, the type of combination is made meaningful by referring the possible combinations sensibly to each other since its semantizations like "tie the hook to the string," or "use the fishing rod to get the gear wheel out of the water" contribute to limiting the activity-options for the player.

IV.

If we look at these admittedly still very sketchy analyses of narrative sequences in MMORPGs and Adventures it becomes clear that we have to distinguish between three types of event-sequences, at least for these genres:

1. The sequence of activities of the player

2. The sequence of events as it is determined by the mechanics of the game, i.e. in quests, but also in the type of setting and the arrangement of objects in ego-shooters or the distribution of mobs with certain levels in different zones.

3. This sequence of events (as mentioned in point 2) understood as a plot, that is: as a sequence of chronologically ordered and causally linked events.

After what has been said so far, the first probably has been described clearly enough. In point $2 \mathrm{I}$ am referring to sequences of events that are defined in the mechanics of the game. Depending on the genre and type of action this can mean clearly defined events or also rather as possibilities. A quest for example describes a clearly defined sequence of events. The arrangement of zones can be one that brings you always to areas where you find mobs that are appropriate for ones own level. Or, the arrangement of these mobs in a zone are rather handicaps for the players through which they can collect experience points at a certain time in their playing-career. Thereby greater sequences of events emerge because there are players of level 10-20 in zone A and some of level 20-30 in zone B etc.

The difference between my points 2 and 3 will best become obvious from an example. If the player in the quest-sequence in Everquest II that I analyzed has won the trust of the quest giver he can travel into the hidden city. From the perspective of the mechanics of the game two flags have been set in order to save the successful completion of two quests. What from the point of view of the plot appears as a causally connected sequence of events from the point of view of the mechanics of the game materializes as the setting of binary flags. Why is this perspective of the mechanics of the game important at all? Because players know about it and behave accordingly. Indeed, the relation of points 2 and 3 is a problem for each computer game and we can assume that the fact that many observers still claim an infant state of computer games has to do with the slow progress of their development.

The more rigorous the sequence of events is organized in the sense of the second point, the fewer event-sequences can be added that are considered meaningful. The more complex the worlds of the game become the more 
independent point 1 will become of point 2 . Certainly it is no coincidence that especially in MMORPGs the narratives of players are so numerous.

Apart from these three event-sequences there are also those that are narrative in a traditional sense: cut scenes informing the player about changes in the game world or texts (for example as narratives of characters in the world of the game that describe past events) or even in form of narrative paratexts. As mentioned above very often these forms have been called 'narrative' and have been seen in contradistinction to the 'interaction' of the game. If we treat these narratives as unimportant because for the gameplay they seem to be insignificant additions then we have constructed a strong opposition, which, however, is intellectually not very satisfying. I also believe that narration in this traditional sense is not a central element of computer games but I do not feel that it is opposed to the organization of event-sequences that are central for computer games or at least for the two genres analyzed here.

But does it then make sense to treat all these different forms of event-sequences in the same way? To my mind, yes: All of them, point 1 excepted, result in the player's awareness of an intelligence that invents the events and their sequence and presents them to him, the main difference between the event-sequences lying in the way in which they are presented. In this perspective the comparison to simulation that sometimes is applied in order to replace the comparison to narration ${ }^{[17]}$ does not seem very productive since it is just this organizing intelligence as counterpart that does not find a place here, even though it is securely established in the world of computer games and its cult of author-designers or in the complaints about bad game-designers. The assumption that the world of the game is an artifact that is intentionally related to the situation of the player is a central element for the inferences of the player to find out what he now can or should do. It is just this minimum assumption that is the foundation for these inferences that lead to a move after having evaluated the possibilities of action.

Let us summarize: In computer games event-sequences are organized and actualized by players. The sequences can be organized more or less rigidly according to the degrees of liberty of the game. From the perspective of the player, at least two important event-sequences will emerge: On the one hand the one that is played by himself, and then the one that corresponds to the mechanics of the game. As a third the meaningful organization of event-sequences in narratives comes into play. It seems to me that the narratology of computer games has to be adapted to this multilayered 'nature' of the medium. If we want to talk of a narration in computer games at all-since regarding the prototype of narrativity it seems to be a borderline phenomenon-it is mainly the organization of event-sequences that we have to be concerned with and the different aspects of these sequences that only in an interactive medium can drift apart to such an extent.

This does not mean that something important has been said about all computer games. But maybe questions about the nature and especially that of all computer games are not very productive anyway.

\section{Appendix}

\section{Everquest II}

The following written record shows the dialogues and activities of a quest which is the beginning of a longer sequence of quests. The reward of this sequence is opening up the frogloks, a froglike race, so that the player can choose a froglok as PC himself. Played on February 2, 2006. ${ }^{[18]}$

The first three quests could be entitled: "Winning the trust of the Frogloks." Here 
one can win the trust of the Frogloks to the extent that one can travel to their village. There, one has to win the trust of their leader with the help of a sequence of further quests.

$1^{\text {st }}$ Quest: The Missing

You say, "Hail, Frup Groaak"

Frup Groaak says to you, "Any of them at all? We were wandering through the vast green lands beyond these walls, when we were set upon by brigands!"

You say to Frup Groaak, "Wait a minute, I don't think I've seen you around here before."

Frup Groaak says to you, "Indeed, I should think not. I was very surprised to see other of our kind around here. I and my brothers managed to make our way here from far to the south."

You say to Frup Groaak, "Far to the south?"

Frup Groaak says to you, "In the depths of the Feerrott. I cannot explain more now - trust is something which must be won, and our home cannot be revealed to those who might wish us harm."

You say to Frup Groaak, "I've no wish to harm you."

Frup Groaak says to you, "Then perhaps you'll wish to help."

You say to Frup Groaak, "l'd agree to that."

Frup Groaak says to you, "The other I came to these shores with, Giidib, set out from the beach in the opposite direction as I."

You say to Frup Groaak, "Which beach?"

Frup Groaak says to you, "I apologize, I do not know the names of places here. T'was quite a ways south east of here, however. There was a great forest situated on the banks above."

You say to Frup Groaak, "I'm sure I can find that."

Frup Groaak says to you, "I would like to see Giidib join me here in Qeynos while I plead our case to your illustrious Queen."

You say to Frup Groaak, "I will set about finding him."

Description of the quest (each player has a quest-book with all open quests with their description):

"A new froglok has washed up on the shores of Qeynos. Frup Groaak bids me seek out [!] a lost compatriot of his, Giidib. Very curiously, no one seems to have heard anything about frogloks outside of Qeynos since the Age of Cataclysms."

In the zone Antonica at the beach we find the tracks of Giidib as well as an indicator for a direction. If we follow these tracks we come to a rock that is only active for those players who are on this level of the quest. Option for activity: "Search around the rock." Result: "Quest journal update! The froglok tracks continue back to the east."

After several such updates we finally find Giidib in a pond and get the task to 
lead him to the next watchtower. Just before arrival Giidib dies without the player having any possibility to prevent that. All we can do is to let Frup Groaak know.

You say, "Hail, Frup Groaak"

Frup Groaak says to you, "I sense from the sadness that surrounds you that something has gone wrong..."

You say to Frup Groaak, "I don't know how to tell you this..."

Frup Groaak says to you, "...but he has gone to the embrace of Marr's mighty arms. This is plainly written in your expression."

You say to Frup Groaak, "He was ambushed before I found him."

Frup Groaak says to you, "Was he able to fend off his attackers at least?"

You say to Frup Groaak, "Yes. It was the poison that did him in."

Frup Groaak says to you, "Poison? This is an assassin's tool. Why would he be hunted in such a fashion?"

You say to Frup Groaak, "I am unsure."

You gain experience!

Frup Groaak says to you, "Allow me to think for a time, and I will commune with Marr. Perhaps he will grant me guidance."

You say to Frup Groaak, "Very well, I shall seek you out later."

From the history book of the Frogloks [The text is contained in a history book of the Frogloks that the player receives and about which he has to be able to answer questions during a quest]:

We are the children of Mithaniel Marr, god of valor. He has given unto us a greater share of honor than was given to any other creature. We would rather die with honor than extend our lives through deception of any kind.

This can be challenging for others-the concept that laws are not meant for the breaking. While we try to be understanding that not everyone shares our belief, it is still distressing to see rules bent and broken. The laws of the land are not simply suggestions, as some seem to think.

Such is the way of the troll. After many attempts to peacefully coexist with them in the Innothule Swamp, their utter disregard for protocol finally provoked us to battle. The blessing of Mithaniel Marr was with us as we drove them from their filthy city of Grobb. In His honor, we renamed it Gukta, Outpost of Marr.

Some may wonder why we contented ourselves with a simple home like Gukta, when our obvious intelligence indicates we might prefer plush surroundings. That is not our way, you see. It seems those whose skin is laced with hair need warmth and softness in their surroundings. We are comforted in other ways.

Others have said that we frogloks are too proud and that we deserve the challenges that have been our lot through the Ages. We do not deny the pride we feel in our heritage. We were created by Mithaniel Marr, after all. Through his grace, we have overcome many adversities that would have brought others to the brink of despair. 
When the ogres of Rallos Zek began their reign of terror, they tried to start with Gukta. They thought they knew all the deepest reaches of our territory, thinking that we had not changed or developed it after wresting the city from the trolls. The ogres fought without honor, to their own detriment.

We are not taken unawares with ease. The foul ogres thought to destroy us, but we were guided by the Hand of Marr. Our eggs were carried deep into the tunnels, followed by elite forces to guard them. Deep beneath the marshes we went. We sent emissaries to Freeport to advise the Overlord of the rise of the Rallosians.

The Overlord brushed our concerns aside and so, with barely three days' rest, our emissaries headed to Qeynos to warn the Bayles. Though sympathetic, they chose only to increase their watches rather than advancing to attack before the Rallosians expanded their reach. How we wished they had listened! The Rallosian Army grew in strength and power until the cities of Freeport and Qeynos were besieged.

The blessings of Mithaniel Marr still protected the faithful. The honorless ogres broke faith with their own allies, defiling the Temple of Cazic-Thule. And so, in the darkest hours when it appeared that the Rallosians would conquer all, the Green Mist covered the battlefields, slaying our enemies. However, not all our enemies were destroyed.

Though many of our adversaries perished in the time of the Green Mist, some escaped by continuing to pursue us. Deeper into the marshes we fled, and still they followed. It was then that we felt the rage of the gods.

By failing to stand our ground and hold back the tide of the enemy, we disappointed the gods who had held us high in their trust and esteem. Punishment was both swift and severe.

Though we had escaped the Rallosians, we could not escape the torments to follow. The Rending kept those of us who had scattered apart. Separated from any other honorable race, we drifted into oblivion.

And yet, oblivion would have been more kind than that which we endured. For those of us who found our way to the Feerrott were taken prisoner by the Tae'Ew, who fed us to their god.

Generation upon generation of froglok has been subjugated by the Alliz Tae'Ew. They demanded service and, weakened by the calamities that had befallen us, we were in no position to rebel. Until now.

In secret, several of our strongest broke free and are repeating the journey made so long ago when we first sent word to Freeport and Qeynos that the Rallosians were on the move. Surely we have atoned for our offenses against the gods and will be saved.

\section{Black Mirror}

The following written record somewhat simplifies matters since the search for active points in the image is one of the main tasks in an Adventure.

If the player clicks on an active object for the first time, he usually receives a lengthy description. Some objects cannot be clicked on any more after the first or second time. Upon further clicking on the others the player only gets a short statement. In the following the number is marked directly after the description of the object.

The exact task is unknown to the player when he enters the sewage system. 
Upon entering: "James did not lie. The secret subterranean system of ducts exists. The air is very stuffy here."

The room has two exits. "Upwards" into the normal basement and "Further down."

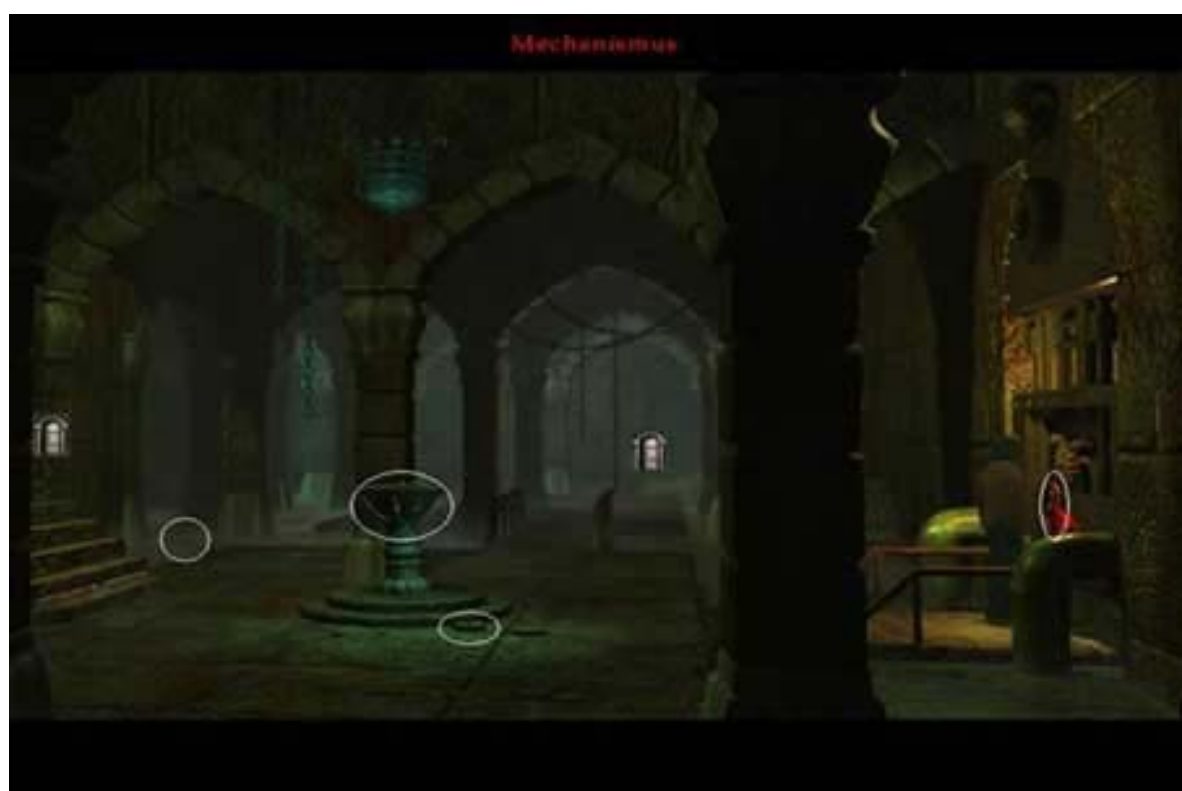

Fig. 3. Strange mechanism in Black Mirror. Interactive objects are marked.

From left to right:

Sewer (1)

First: "This intricate sewage system was built by my ancestors."

Well (3)

First: "What could a well in the basement serve? Maybe one could get water from down below, when the castle was besieged. The water here could not be drunk without problems. It is too brackish."

Description: 1) "There is not a drop of water in it." 2) "It is empty."

Gear wheel (1)

First: Gear wheel ${ }^{\circledR}$ inventory.

Description (in the inventory): "Where could this fit?"

Mechanism ( $\infty)$

First: "This mechanism probably regulates the pumps in the basement. It certainly can't have been standing here since antiquity."

Description: "It seems to be jammed."

Activities:

"Combine gear wheel (inventory) with mechanism." Result: 


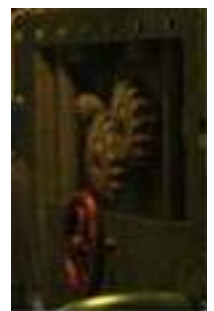

Fig. 4. The strange mechanism; obviously one wheel is missing.

The description of the mechanism has not changed.

$2^{\text {nd }}$ Image:

Upon entering:

"The air in here smells horribly. It smells stale. There hasn't been any fresh air here for centuries."

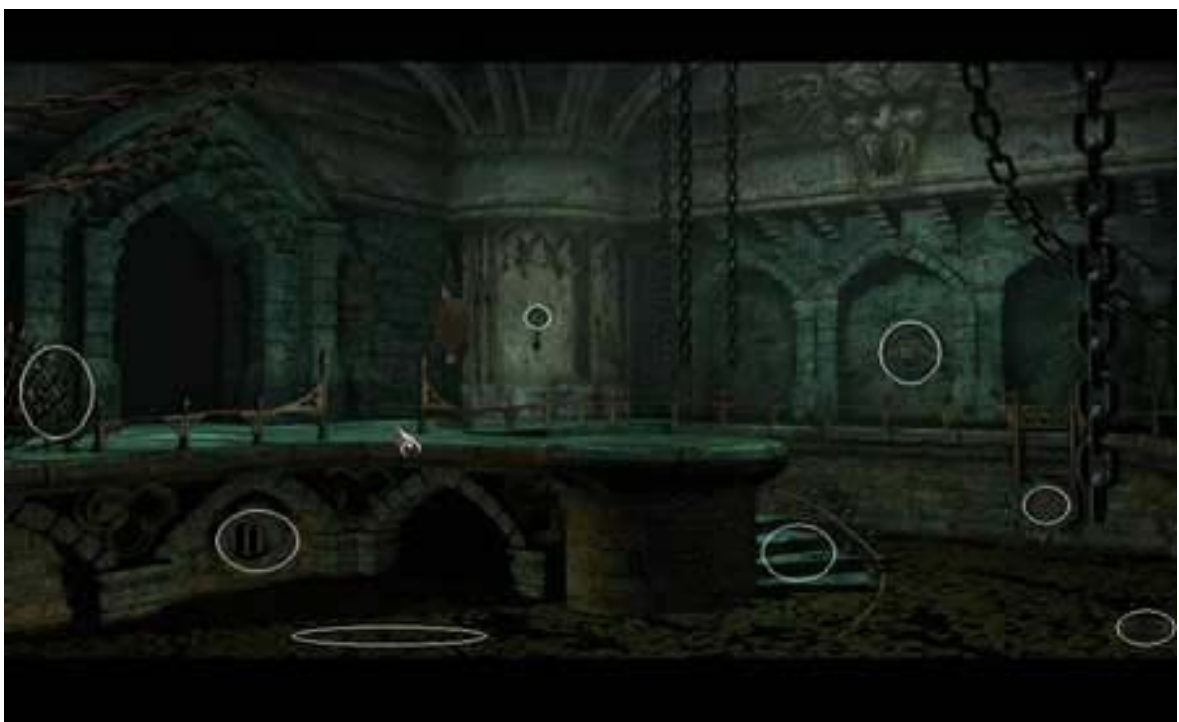

Fig. 5. Searching in the missing wheel.

Banister (1)

First: "It's rusty from the humidity. One of the bars is loose." Bar ${ }^{\circledR}$ inventory.

Sewage shaft (1)

First: "Probably that's where the water runs out when it overflows."

Dirty-cloudy water (1)

First: "The water must have been sitting here for years. It is full of algae and dirt."

Opening a $(\infty)$

First: "Some kind of opening. Maybe something is missing here."

Description: "Some kind of opening. Maybe something is missing here."

Stairway (1)

First: "The stairs can't be used. They are completely under water."

Wheel $(\infty)$ 
First: "I can't turn it at all. It is blocked by chains that are secured with a padlock."

Description: 1) "It can’t be turned." 2) "I can’t turn it at all."

\section{Opening $b(1)$}

First: "I think this is where the water flows. But this probably hasn't happened for a long time."

Gear wheel: $(\infty)$

First: "Part of a machine. There are so many algae in the water it didn't sink. How can I get it out of there?"

Description: 1) "From here I can't reach it." 2) "It is too far away."

\section{Activities}

1) Try to combine the bar (in the inventory) with the opening a.

"I will try to put the bar in there."-"It doesn't work. The bar is too fat."

2) Go into the basement above and grind the bar down to a point

3) Combine the bar with the opening a.

"With this it should be better. I will try using the bar as a lever." (Hatch by opening $b$ has opened.) "The hatch has opened, but the water isn't running out."

4) Combine the acid (from the inventory) with the wheel.

"The acid has dissolved the padlock as if it were made of paper."

5) Turn the wheel.

Water comes through opening b. Short blackout. New image "The water has risen to the edge of the drain pipe."

6) Combine hook (in inventory) with rope (in inventory). Combine rope with pointed rod. "A primitive fishing rod. It will have to do."

7) Combine fishing rod with gear wheel, Samuel catches the wheel from the water. Gear wheel ${ }^{\circledR}$ inventory.

8) Combine the gear wheel with the mechanism from the first image. Now the wheel can be turned.

"It has worked. The mechanism is functioning."

The water is flowing out. Upon entering the back part: "All of the water has flown out to the subterranean sewage system. The road is clear." At the end of the stairway now lies a small case with the key. 


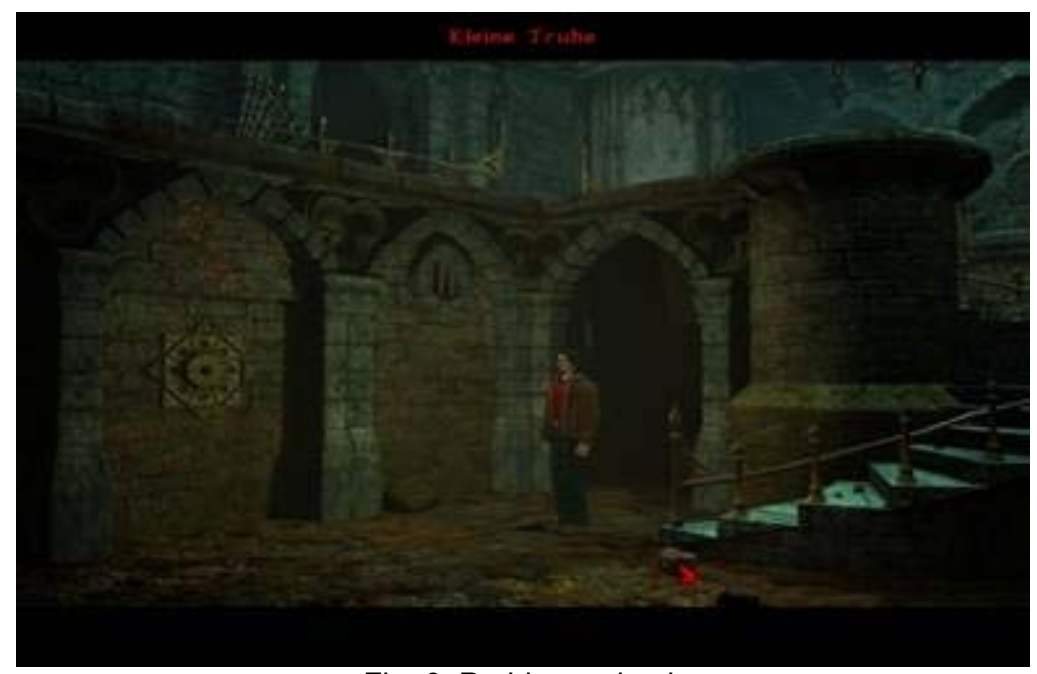

Fig. 6. Problem solved.

Translated from German by Brigitte Pichon and Dorian Rudnytsky

\section{Works Cited}

Black Mirror: The Dark Side of Soul. Future Games, 2003.

DeMarle, Mary. "Nonlinear Game Narrative." Game Writing: Narrative Skills for Videogamers. Ed. Chris Bateman. Boston: Charles River Media, 2006. 71-84.

Eskelinen, Markku, and Ragnhild Tronstad. "Video Games and Confi gurative Performances." The Video Game Theory Reader. Ed. Mark J. Wolf and Bernhard Perron. New York: Routledge, 2003. 195-220.

Everquest II. Sony Online Entertainment, 2005.

Frasca, Gonzalo. "Ludologists Love Stories, too: Notes from a Debate that Never Took Place." Level Up. Digital Games Research Conference 2003 Proceedings.

Ed. Marinka Copier and Joost Raessens. Utrecht: Universiteit Utrecht UP, 2003. 92-99. 7 July 2006 <http://ludology.org/articles/Frasca_LevelUp2003.pdf>.

$\begin{array}{cccccr} & \text { "Ludology Meets } & \text { Narratology: Similitude } & \text { and } & \text { differences } & \text { between } \\ \text { (video)games } & \text { and } & \text { narrative." } & 7 & \text { July } & 2006\end{array}$ <http://www.ludology.org/articles/ludology.htm>.

Hartmann, Bernd. Literatur, Film und das Computerspiel. Münster: Lit Verlag, 2004.

Jannidis, Fotis. "Narratology and the Narrative." What is Narratology. Ed. Tom Kindt and Jan C. Meister. Berlin: de Gruyter, 2003. 35-54.

Juul, Jesper. Half-Real: Video Games between Real Rules and Fictional Worlds. Cambridge, MA: MIT Press, 2005

Kent, Steven L. The Ultimate History of the Video Games. Roseville: Prima Publishing, 2001.

Lischka, Konrad. Spielplatz Computer: Kultur, Geschichte und Ästhetik des Computerspiels. Heidelberg: Heise, 2002.

Mertens, Mathias, and Tobias Meißner. Wir waren Space Invaders: Geschichten vom Computerspielen. Frankfurt am Main: Eichborn, 2002. 
Poole, Steven. Trigger Happy: The Inner Life of Videogames. London: Fourth Estate, 2000.

Ryan, Marie-Laure. "Beyond Myth and Metaphor: The Case of Narrative in Digital Media." Game Studies 1.1 (2001). 7 July 2006 $<$ http://gamestudies.org/0101/ryan/>.

Salen, Katie, and Eric Zimmerman. Rules of Play: Game Design Fundementals. Cambridge, MA: MIT Press, 2004.

"Spielspiel, Teil 2." Games Entertainment Education, April 2006: 56-60. 7 July 2006 <http://www.geemag.de/relaunch_storyseite.php?story=72\&ausgabe=20>.

"Tome of Destiny." Everquest II Online Gaming Network. 7 July 2006 <http://eq2.ogaming.com/data/1862 TomeofDestiny.php>.

Wallace, Mark. "The Play's the Thing." The Escapist 36 (2006). 7 July 2006 $<$ http://www.escapistmagazine.com/issue/36/13>.

Walter, Klaus. Grenzen spielerischen Erzählens: Spiel- und Erzählstrukturen in graphischen Adventure Games. Siegen: Universi, 2002.

Wolf, Mark J.P., ed. The Medium of the Video Game. Austin, TX: U of Texas P, 2002

[1] The debate was far-reaching and fierce. Cf. its summary in Frasca, "Ludologists". Frasca's seeming peace-offer primarily defends ludologists against a series of reproaches and a number of suggestions for additional literature are given as well. On the side of narratologists I would specifically mention the contributions by Marie-Laure Ryan and on the side of the ludologists the ones by Markku Eskelinen. A good discussion of the different approaches can be found in Hartman: "Computerspiel", p. $57 \mathrm{ff}$. An intellectual low point of the whole debate can be found in an essay by Mark Wallaœ whose contribution is full of anti-intellectual resentment. Cf. Mark Wallace: "The Play's the Thing." On the other hand there is a lot of research which isn't interested in these kinds of questions, e.g. the histories of computer games, cf. Kent: "History", Lischka: "Spielplatz" or Mertens / Meißner: "Space Invaders".

[2] Aarseth, Eskelinen, Frasca, and Juul probably are the most well-known ludologists; cf. the literature in Frasca, "Ludologists."

[3] A similar argument has been made by authors who are not related to the game studies at all, like the journalist Steven Poole in his book Trigger Happy, who claims that stories are only important as back-ground or as the non interactive parts of the games, but on the other side thinks that these parts of games will become more important in the future; cf. Poole "Trigger", p. 103ff. or cf. Walter: "Grenzen". Wolf tries to reconcile his notion of narrative with the interactivity of computer games but states at the end that for many the storyless game experience will be the prototypical; cf. Wolf: "Medium", chapter 5.

[4] In my opinion it is an interesting consequence of this approach that a general narratology is quite impossible; rather, there exist only narratologies relating to particular media. 
[5] The notion of gameplay is notoriously fuzzy. As I understand it in the following it is the type of choices and options or activities that a player has in order to reach his goal. This is often not differentiated from the experience of the game but is seen as a central unit for the design of games. Cf. e.g. the statements of game-designers in "Spielspiel, part 2" in Games Entertainment Education, April 2006: 56-60.

[6] E.g. the so-called Peacock or the Claymore quest lines in Everquest II.

${ }^{[7]} \mathrm{Cf}$. the record in the appendix.

[8] In Everquest II, like in most computer games today, also ones own contributions to the dialogues are given by the game. However, at each move in the game the player has the possibility to continue the dialogue or to break it off.

[9] At the beginning only certain zones could be entered if one had completed an entry-quest. This was abolished for all zones that were important for all players and it was retained only for special quest- and raid-zones.

[10] Cf. <http://eq2.ogaming.com/data/1862 TomeofDestiny.php> (accessed April 1, 2006).

[11] For the text of this lesson cf. the appendix.

[12] The reward always consists in experience points, but in addition can also be money, an improvement of the faction or an object.

[13] Of course we could ask why he takes the trouble to break the family curse since with his death as the last family-member the family is extinguished.

${ }^{[14]}$ A very detailed analysis of the functioning of adventure games can be found in Walter.

[15] The basis of the following analysis is the detailed summary in the appendix.

[16] Therefore, in some Adventures there are quest-diaries that inform the player about the current goals, Ankh for example.

${ }^{[17]}$ Cf. the above-mentioned contributions by Frasca.

[18] Since MMOPRGs constantly change, it is necessary to note the date of playing.

dichtung-digital 